Title: The moral order in family mediation: negotiating competing values Paper accepted for Conflict Resolution Quarterly 13.01.17

Authors: Janet Smithson ***, Anne Barlow, Rosemary Hunter and Jan Ewing

Dr Janet Smithson

School of Psychology,

University of Exeter,

Washington Singer Building,

Perry Road

Exeter, UK.

EX4 4QG.

Email: J.Smithson@exeter.ac.uk

Fax: +44 (0)1392 724623

Tel: +44 (0)1392 724635

Professor Anne Barlow,

School of Law

University of Exeter,

Amory Building

Rennes Drive

Exeter, UK.

EX4 4RJ.

Email: A.E.Barlow@exeter.ac.uk

Fax: +44 (0)1392 722045

Tel: +44 (0)1392 723159

Professor Rosemary Hunter

School of Law

Queen Mary University of London

Mile End Road

London E1 4NS

Email: Rosemary.hunter@qmul.ac.uk

Tel: +44 (0)20 78823984

Dr Jan Ewing

School of Law

University of Exeter,

Amory Building

Rennes Drive

Exeter, UK.

EX4 4RJ.

Email: j.ewingw@exeter.ac.uk

Fax: +44 (0)1392 722045

Tel: +44 (0)1392 723159 


\title{
The moral order in family mediation: negotiating competing values
}

\begin{abstract}
We used Discourse Analysis to study how mediators and parties negotiate competing priorities and values during the family mediation process. We drew on understandings of practical morality, and specifically the concept of a moral order, to study UK mediation session talk. Our analysis highlighted the contradictory moral orders drawn on by parties and mediators. The saliency of moral categories and concerns in parenting is demonstrated, and we consider the problems this causes in the "no fault" context of mediation.
\end{abstract}

Keywords: Family Mediation, Discourse Analysis, Moral Order.

\section{Introduction}

In the UK family mediation system, separating adults attend mediation sessions with the goal of reaching an agreement about finances and/or child contact arrangements after separation or divorce. This is facilitated by a mediator, trained by one of a number of mediation organizations. A core aim of mediation, which is highlighted in the training, is the importance of neutral or impartial facilitation which enables participants to come to their own decisions (Family Mediation Council 2016). However, mediators are also encouraged to steer participants towards a "fair" outcome in terms of sharing financial assets, and care of children (Webley 2010; Robinson 2012). They are moreover supposed to ensure that, for parents, the" best interests" of the child or children are prioritised.

A dilemma in all types of mediation is therefore how to balance a neutral or impartial facilitation which enables participants to come to their own decisions, with a more directive 
approach which attempts to steer participants towards what lawyers would consider a fair outcome (Webley 2010; Robinson 2012). In practice, mediators need to manage these competing expectations, or to prioritize some over others (Greatbatch and Dingwall 1989). This tension between several of the core values of mediation is noted in training and reflection on practice, but there is little detail in training manuals about how mediators might attend to competing expectations and values during the mediation process itself.

\section{Features of mediation talk}

Mediation shares some general characteristics of institutional talk (Drew and Heritage 1992), and with counselling and therapy encounters in particular. In common with other counselling and therapy encounters, in mediation there is an interactional asymmetry between practitioner and participant(s), lay versus professional, which sets up and is characterized by specific turn-taking procedures, agenda-setting, formulation and preferred types of responses (Heritage and Greatbatch 1989; Mondada 1998; Hutchby 2005). It is goal-oriented, with some forms of talk permitted and others discouraged, and participants attend to their institution-relevant identities (e.g. as mediators or as parties). The mediators are trained to adhere to a code of practice, which includes a set of explicitly laid out mediation ideals and norms, although, as previous studies have demonstrated, there are often gaps between normative ideals and actual practice (Garcia 1991; Dingwall and Greatbatch 1993; Greatbatch and Dingwall,1997). In particular, the concept of mediator neutrality has been shown to be difficult to achieve in practice in various studies (Cobb and Rifkind 1991; Greatbatch and Dingwall 1999; Jacobs 2002). Mediators, in common with therapists and counsellors, often struggle with talking about responsibility and behavior in a "non-blaming" neutral setting, and particularly when they are dealing with two parties, or clients, at once in a multi-party situation (Patrika and Tseliou 2016). Kelly (1983) outlined some of the key distinctions between mediation and therapy - in particular, the selectivity of focus in 
mediation, and the orientation to outcomes; "The goal is not to cure the conflict but to redirect and manage it sufficiently well to enable the couple to reach agreement (Kelly 1983, 38). However, Kelly also noted that mediation is on a continuum, with some practitioners, who may be trained therapists, more focused on emotional issues and others (often trained solicitors) concentrate on legal aspects. Some researchers, such as Tjersland (1997), have explored how mediators might deal therapeutically with emotional issues in the mediation process. However, Merry (1990) argued from an ethnographic study of US mediation talk that the mediation setting itself encourages "rival ways of talking about problems and events" (Merry 1990, 3), which she identified as moral, legal and therapeutic discourses. She demonstrated how both mediators and parties switch between these discourses "when one seems unproductive or leads to trouble" (Merry 1990, 4), but she found that the moral discourse predominated in (US) mediation settings. Baitar, de Mol and Rober 2016) argued that we should take a relational approach and acknowledge the interplay of complex and contradictory processes which may occur during mediation (Baitar, de Mol and Rober 2016). An investigation of some of the complex and contradictory aspects within the mediation dynamic may offer insights to mediators and training organizations.

\section{Values and morality discourses in mediation: the Moral Order}

In contrast to studies focusing on how mediators talk "about" their mediation practices or values, we use Discourse Analysis (DA) to attend to the details of talk in mediation sessions, (e.g. Dingwall and Greatbatch 1993; Greatbatch and Dingwall 1997; Stokoe $2013 ;$ 2014). This approach is particularly suited to study tensions between competing values (Jacobs 2002). Webley assessed UK mediator training; and concluded that the training is primarily "values and skills-based", with priority being given to a "consensus-based approach" (Webley 2010, 126), even though this may lead to what family lawyers consider an unfair settlement. Bergmann (1998) wrote that "in health care, in social work and education, 
in counselling and therapy, [practitioners] have taken on tasks that traditionally involve moral issues. However, they work within institutions that function according to "rational" models and criteria, and they therefore are officially constrained to "demoralize" issues, couching them in terms of scientific or bureaucratic rationality, and taking a "neutralistic" stance with respect to the problems they deal with" (Bergmann 1998, 291).

In this paper we explore how these contrasts between competing values are exhibited and dealt with in mediation sessions where parents discuss child arrangements after separation. Our discursive approach draws on understandings of practical morality that is, morality is practically realized in the practices of self-presentation and face work (Goffman 1959; Garfinkel 1967; Bergmann 1998; Sterponi 2003), also sometimes termed "mundane morality" (Stokoe and Edwards 2015). We draw on the concept of the moral order, which has been used by researchers in a number of studies of talk in therapeutic and counselling institutions. Wahlström (2016) describes the moral order as "more or less articulated and shared understandings of what is valued and what is not, what are the loyalties, duties, and responsibilities expected from the partners, and the grounds for evaluating actions. It also includes expectations concerning how value, concern, and respect are communicated" (Wahlström 2016, 149). The concept of a moral order has been taken up by discourse analysts, as it provides a way of understanding value-based discourse as a "continually constructed and renegotiated understanding of rights and responsibilities, good and bad" (Kurri 2005, 11). Kurri and Wahlström $(2001 ; 2005)$ showed how counsellors managed to stay neutral yet give advice by marking the act of preferring charges with delicate discursive devices, simultaneously giving space to the impression of the private sphere of family and marriage as a domain of autonomy and inviolability, while producing counselling as a domain of power and interference with the client's autonomy. Hutchby and O'Reilly (2010) demonstrated how participation in family therapy sessions is informed by differing agendas 
and a "familial moral order". Cromdal and Tholander (2014) argued that "when engaging in agreements or disagreements, when questioning or accounting for certain forms of behavior, when praising, blaming or otherwise assessing their own and one another's actions, members invariably invoke and reflexively produce moral orders" (Cromdal and Tholander 2014, 10). Features of moral talk which indicate the moral order can be direct, e.g. by morally loaded vocabulary (Bergmann 1998), or indirect, "traces of morality" such as expressing disapproval or offering sympathy on telephone helplines (Potter and Hepburn 2015).

Family mediation talk covers value-laden topics such as responsible parenting, fair division of finances, elements with strong moral expectations, and the mediator needs to navigate this emotionally fraught territory to facilitate the parties to reach an agreed outcome in terms of child contact and financial arrangements after a separation or divorce.

Consideration of the moral order in mediation discourse gives us a way of understanding how explicit and implicit societal norms around family, parenting, divorce, marriage, gender and the role of the law affect the mediation process.

\section{Data}

The data studied here is from mediation sessions involving adults attempting to agree about child contact arrangements after separation or divorce, facilitated by a trained mediator. The data come from a three-year, ESRC-funded academic research project undertaken by the Universities of Exeter and Kent. We conducted a national survey of out of court dispute resolution awareness and experiences, an individual interview study with 95 people who had experienced an out-of-court family dispute resolution process between 1996-2013, and 40 individual interviews with practitioners of dispute resolution processes. The findings from the survey and interview data are fully described in Barlow, Hunter, Smithson and Ewing (2017); see also Hunter, Barlow, Smithson and Ewing (2014; 2015). For the final phase of the study we audio-recorded 25 dispute resolution sessions, including nine mediation sessions 
involving five couples. In this paper we consider data from the recorded mediation sessions. Ethical approval was obtained from the University of Exeter, and all participants were provided with information beforehand about how their data would be used, and consented to this. All names and identifying features have been changed.

\section{Discourse Analytic approach}

In this paper we use a Discourse Analysis (DA) framework to study participants' talk about values, morals expectations and ideals in family mediation sessions. In DA, talk is treated as a social action through which participants use a range of discursive devices to explain, justify, give and refute advice and make persuasive arguments. In our analysis we attended to the function of discourse: what is accomplished by a particular discursive construction, as evidenced in the participants' response? Another feature of DA which we draw on here is the acknowledgement, or the expectation that there can be several competing and contradictory discourses operating concurrently in a given situation (Locke, 2009). DA can help us consider how these are managed concurrently. For example, how do mediators and parties negotiate the competing, and contradictory expectations inherent in the mediation process? Finally, an investigation and acknowledgement of power dynamics is important to DA (van Dijk 1993), and we consider the power dynamics of these mediation encounters (Winslade 2006), and the ways in which discourse structures "enact, confirm, legitimate, reproduce, or challenge relations of power abuse (dominance) in society" (van Dijk 1993, 467), In a discursive approach, a single or few cases, analyzed in detail, are assumed to shed light on widespread practices and assumptions, and also highlight future areas of study (McHoul and Rapley 2005). The examples of mediation session talk included here have been selected to illustrate instances of moral positioning by parties or mediators, and instances of competing sets of values, or tension between values and practice. We looked for: 1) examples of expectations and orientation to particular goals or values at the start; 2) direct 
reference to values or morality during sessions; and 3) value-oriented strategies which mediators used when parties did not manage to agree.

\section{Analysis}

\section{Values and norms in agenda setting}

In these UK family mediation sessions, both parties will normally have previously attended separate Mediation Information and Assessment Meetings (MIAMs). The first joint mediation session typically starts with an introduction to the session format, signing an agreement, and setting out expectations. Extract 1 is the point early in this mediation session when the general introduction to the format is over and the mediator moves on to the couple's agenda:

Extract 1: Jordan and Nicola (9 minutes into session)

1. Med Ok (.) um so what (.) I mean in terms of an a:genda here because it's up to 2. you to set the agenda for today and (.) I know I know that you both want to 3. talk about [child] and the arrangements for him but are there any specifics I

4. don't want to get to the end of the session and you say, actually we haven't

5. mentioned that incident that happened last Friday and (.) you know it was

6. really difficult (.) So is is it just the arrangements for [child] or is there

7. anything else that you would like to talk about

8. Jordan No no (0.2)

9. Med Nicola?

10. Nicola No, well uh uh Jordan initiated this mediation session so (0.2)

11. Med Yeah

12. Nicola so (.) um (0.2) and I only obviously got clarification in terms of what (.) um 13. what he was looking for when I came for my pre (.) meeting (0.2)

14. Med Ok 
15. Nicola So:o um I am assuming it's just (.) that it is contact arrangements

16. Jordan It's um it's always contact arrangements the discussions that

17. Nicola Yeah

18. Jordan basically we have is

19. Nicola contact yeah

20. Jordan about contact and ongoing so (.)

21. Nicola So specifically probably I would like to cover Christmas as part of that

22. Med Oka:ay so that would be good to get that discussed whilst you are here

Here the mediator introduces the idea of having an agenda for the session (line 1), and tells the parties it is "up to you" to set the agenda, but immediately (line 2) adds "and I know that you both want to talk about the child". The expectation for the session is: there will be an agenda, but the parties set it (and this will have been discussed in the separate MIAMs before the joint mediation); however there is an expected content which has a strong moral tinge - cooperative participants in family mediation will orient to their child's contact arrangements. It may be that the mediator is referring here to priorities raised in the MIAM. This opening, while ostensibly giving choice to the parties, is also a reminder of the agenda in the mediator's view, and the appropriate topics in this type of activity. Then the mediator offers a chance to add "specifics". One party (Jordan) immediately agrees to this proposed agenda without additions (line 8). The mediator then asks the other party, Nicola, directly, and her response makes her sense of limited agency clear: "No, well, Jordan initiated this meeting". Her next comment "I only obviously got clarification" draws attention to her late knowledge of the process and issues. Nicola thus highlights her lack of agency and outsider status in the mediation process, positioning herself as less knowledgeable, in contrast to Jordan. Garcia (1991) outlined the interactional techniques which participants use to 
construct effective opening statements in neighborhood mediation - crucial in setting up positions and aligning oneself in a particular way, and relevant for the mediator's efforts to balance power between disputants. Having highlighted her outsider status, Nicola then does add to the agenda, and the mediator takes this up as relevant, thus carefully involving the reluctant participant with a "subtle nudge" (Potter and Hepburn 2015) towards appropriate involvement.

Extract 2: Martha and Jacob (5 minutes into session)

1. Med ... we are here today really to talk about the uh current arrangements (.)

2. uh we can wind that out to your role as parents, your communication

3. um and uh whether there are any concerns, the welfare of the kids uh

4. but (.) focusing perhaps primarily on what the mediation was set up

5. for (.) which is to see what the arrangements are for the children and

6. whether they're uh whether they are the right ones and what your

7. thoughts and feelings are about that (.) Uh, so would you both like to

8. $\quad$ sort of say (.) really what you hope to achieve from this meeting? (0.2)

9. Jacob: Me, um I mean as I said before I just want to understand the reason

10. (.) why Martha is refusing (.) the kids to come over to my place and

11. also recently I have asked if we can extend the hours (.) at least to 4

12. hours and to see the kids (.) every week, more like every weekends (.)

13. um just to build up my relationship with the kids as well and also

14. change the locations (0.2) I just want to get a clear understanding why

15. she is refusing that and is there anything we can do to, to make it better $(0.3)$

16. Med Um (.) well don't you well um you can either sort of directly respond to

17. that or say if there is generally other things that you would like to focus on

18. as well. 
19. Martha Uh. For the contact center we have already discussed that with the solicitors

20. and (.) uh Mr O’Neil here he knows the reason why we (.) uh we can't

21. change the contact center, one being that the cost of the one that he chose

22. it was too high (...) it is very expensive compared to where I am paying at

23. the moment (.) uh the reason why the kids cannot come overnight he or to

24. his place he hasn't mentioned that before but privately Mr O'Neil knows why

25. the kids can't go to his house because of my belief and because of the moral

26. of how I am raising the children and I just believe that the children are very

27. young to be exposed to um (.) the kind of lifestyle that he is living (.) um I

28. am not judging, I am not condemning (.) but he has chosen what to live, how

29. he wants to live.

In this extract we see a (different) mediator adding to the agenda (again, this is likely to be drawing on the initial MIAM discussions), "what the mediation was set up for" (line 4). She elaborates on this: "what the arrangements are for the children and whether they are the right ones". The agenda-setting thus has strong moral expectations of what is right in this context. The mediator invites the participants' "thoughts and feelings"; to say what they "hope to achieve". Jacob responds with a list of aims (lines 9-15). This agenda is complex, combining practical arrangements (extending contact hours, changing the location of contact) with emotional input “just to build up my relationship with the kids", and a wish (line 9, repeated line 14) to "understand" Martha's resistance. He concludes with "is there anything we can do to make it better". Jacob thus demonstrates his appropriate moral stance as loving father keen to improve his relationship with his children, struggling to understand - and thereby positioning as unreasonable - his ex-partner's resistance to this morally appropriate behavior. 
Martha is invited to do one of two things (lines 16-18): to either directly respond to Jacob's agenda, or add her concerns. She produces an elaborate response to Jacob's location concern, how this has been "already discussed" with solicitors. "Mr O’Neil here knows the reason". This response draws attention to her reasonableness and appropriate moral behavior - discussions with solicitors - and implies that his reasonableness here is a performance for the mediator. The use of formal language "Mr O'Neil" might be a way of distancing herself from the previous intimate relationship, or as a way of demonstrating competency in layprofessional interactions (Atkinson, 1982; Edwards and Potter, 2001). Martha then addresses Jacob's first point, why the children cannot go to his home. For this she uses overtly moral discourse (Bergmann, 1998) - her belief, and "the moral of how I am raising the children" importantly, not "exposing them" to Jacob's "lifestyle", even though she is "not judging" (line 28). Martha thus demonstrates that her prevention of extended contact is tied to her particular moral beliefs about parenting as a mother, and not to a more questionable general intolerance or prejudice toward her ex-partner as a person. She simultaneously underscores the agency of Jacob's choosing this immoral lifestyle (Extract 2, line 13), which pre-empts a possible inference that he is the victim in this scenario and lacks the agency to alter the current state of affairs.

\section{Direct moral discourses: the problem of trust}

Martha's direct moral discourse can be seen throughout their mediation session, for example:

Extract 3: Martha and Jacob (40 minutes into session)

1. Martha you have to understand that this whole thing (.) blew up (.) because of

2. that hospital incident (.) and til this very day Jacob you don't

3. understand your mistake (.) I can't trust somebody that ok they

4. don't they don't understand what they are doing is wrong and then me 
5.

6.

7. automatically just handing my children over (.) it doesn’t work like that I have got to build your trust, I have got to trust Jacob I am giving you these kids yeah?

Martha tells Jacob that there is a problem with him not understanding his "mistake", and therefore not being trustworthy. She prefaces her assertion with "til this very day", which frames Jacob as incorrigible, and strengthens her argument that he is not responsible enough to be entrusted with the care of 'her' children. Here she addresses her expartner directly as Jacob here, in contrast to referring to him indirectly as "Mr O'Neil" (Extract 2). In these mediation sessions, parties shift from addressing each other directly, and speaking to the mediator, often about the other party (Garcia 1991; 2010). In this way, complaints do not have to be articulated, yet a "complainable" can be present indirectly in an interaction (Schegloff 2005). In Extract 2 Jacob talked about wanting to "build up my relationship with the kids". Martha now talks about needing to "build" her trust in Jacob. The aim of mediation is often practical, for instance to agree contact times and locations, but for Martha the dominant issue is of being able to trust Jacob. Her moral stance draws on her identity as a good mother who protects her children from inappropriate ideas, activities and relationships. Although mediation norms - along with UK family law in general - start with a presumption that close involvement with both parents is in the best interests of the children, for Martha, her moral concern trumps the obligation for contact (for analysis of the discourses around the child's best interests in the mediation data, see Smithson, Barlow, Hunter and Ewing 2015). We can see the conflict between Martha's identity as a good mother concerned with the welfare of her children on the one hand, and the mediation demand for her to be a cooperative ex-partner working collaboratively.

The following two extracts are taken from a session with two mediators: 
Extract 4: Kerry and Jack (10 minutes into first session)

1. Med1 So (.) what's happening at the moment in terms of contact

2. Kerry I stopped him from seeing him

3. Med1 So has that stopped altogether

4. Kerry Until today (.) until we've sorted it out today because he lied to me (.) and

5. he has been sneaky (.) and I don't trust him (0.2) hhh (.) I don't like

6. $\quad$ being lied to $(0.2)$

7. Med1 So would it be a good idea to just (.) talk through what you (.) what your

8. Kerry [well

9. Med1 [worries are about (.) not trusting him.

10. Kerry Well it's not that it's the fact that when he went on holiday (.) he left his son up

11. in (Jack's parents' home town) (.) without telling me I'd have preferred to

12. have known to have a choice

When the mediator asks about the current contact arrangements, Kerry states that she stopped Jack, the father, having contact. She provides a justification (lines 4-5) - Jack has lied, been sneaky, she does not trust him. She also links this to her preferences: "I don't like being lied to". As with the previous extracts, the contact problems are described in terms of moral and/or emotional concepts. Lack of trust, due to dishonesty, is relevant for Kerry as a reason to stop contact. In everyday talk, blame constructions (Kurri and Wahlström 2005; Wahlström 2016) are often responded to with face-saving or counter-blame from the blamed party, who needs to account for their behavior. In mediation, in the extract above, the mediator steps in to deflect (or neutralize?) the accusations. The mediator's response here (line 7) is a suggestion they "just (.) talk through", which may be an attempt to produce consensus, but the use of the term "worries" is received problematically by Kerry. The 
mediator asks for details, drawing on a therapeutic discourse - "what your worries are about not trusting him". Kerry resists this shift of focus onto the therapeutic concept of "worries", which is potentially hearable as not based in reality. As Edwards (1999) showed, "worries" can either be constructed as realistic assessments of the situation, or as a subjective, even neurotic, personality problem. Kerry produces an example of when Jack was not honest, in her view, during his time with the child. The trust issue here is not merely her emotional problem to be worked on therapeutically, but is explicitly linked to a parenting action which Kerry is unhappy with.

Later in this session:

Extract 5: Kerry and Jack (60 minutes into first session).

1. Kerry [I suppose more lies are going to keep coming out

2. Med2 [It's great that you have taken a step forward but most couples find it

3. takes a while to rebuild trust [and so trust

\section{Kerry \\ [I don't trust him}

5. Med1 And so trust is obviously a big issue for both of you isn't it and (.) most

6. couples find it does take a while [to reach that

7. Kerry

[I don't know why he can't not trust $\underline{\text { me }}$

8. I have never ever given him one reason not to ever not trust me ever, never

9. Med2 And what most people find is that they actually have to see things

10. working (.) that they actually have to see arrangements working and that

11. they actually have to see the communication taking place (.) in a different

12. way

Kerry refers again to "lies" and the second mediator picks up on this moral discourse and reframes it to repair the conversation (lines 2-3), repackaging Kerry's mistrust of Jack as not 
realistically based on Jack's conduct but rather as a phase that "most couples" go through. While Kerry views "trust" as an absolute quality which she does not have (line 4), the mediator takes "trust" as a goal for the parties to "rebuild". Kerry challenges this depiction using "never ever", an extreme case formulation (Pomerantz 1986) stressing Jack's limitations in this respect, and her moral blamelessness. Mediator 2 then suggests a practical change, which challenges Kerry's position that Jack would need to first display himself as trustworthy before he can have access to the children. Mistrust is thus categorized as the normal experience of separation itself rather than as an objectively based, realistic and unidirectional concern about the trustworthiness of one particular parent. Kerry's mistrust is normalized and generalized, rather than being seen as a particular mother's understandable reaction to an unreliable father). The mediator, thus attempts to mitigate the couple's disagreement, and makes them more mutually accountable, adhering to mediation values of developing mutually acceptable solutions, and avoiding moral blaming.

\section{Mediators drawing on moral ordering when there is a lack of progress}

In the next extract, with the couple from Extract 1, a mediator uses a moral imperative at a point of disagreement between participants:

Extract 6: Jordan and Nicola (35 minutes into session)

1. Jordan I can't agree to that kind of access (...) So (.) um if we end 2. $\quad$ up in court $(0.2)$

3. Med Can I just say that you seem to have been doing a pretty good

4. job up to now (.) you have got this very happy little chap

5. Jordan [yes

6. Med [that has a very happy time at both homes and you (.) you

7. mustn't lose sight of that. 
Jordan disagrees strongly with Nicola's proposed contact, "I can't agree" and mentions that they might end up in court. This hypothetical "so if" can potentially be heard as a threat of going to court. At this point the mediator intervenes, with "can I just say", a conversational practice which Silverman (1994) has linked to delicate talk, and Kurri and Wahlström (2001) suggest that conversational devices such as this work to demonstrate moral delicacy in conversation. The mediator focuses on the parents' good work in parenting; despite the disagreements. This "pretty good job" is upgraded to "a very happy little chap" as evidence of the good job the parents are doing in raising their child. The child's undisputed happiness and good adjustment provide a warrant for continuing contact. They have a happy child and "mustn't lose sight of that". There is a value invoked here within the compliment, as an explicit value of mediation, one set out at the start of the process, is that parties should focus on the "best interests of the child" (Smithson et al. 2015; Ewing, Hunter, Barlow and Smithson 2015). It may also be a rebuke to having lost sight of the mediation goals or norms at this point in the process. As with the previous extract, the mediator steers the participants away from talk of solicitors and courts; effort is made to improve participants' communication out of court (for more on this, see Barlow et al. 2017).

The same couple is in the next extract, at this stage the mediator is attempting to conclude the session, but the parties have not reached an agreement about child contact arrangements.

Extract 7: Jordan and Nicola (60 minutes into session)

1. Jordan And what the Judge did say is that it was below the watermark and the two of us better sort it out (.) and if we arrived in front of him again he would frown upon it now I have tried everything (.) I have tried to come to some kind of conclusion and agreement with you (.) and

5. there's a paper trail to it (.) 
6. Med Um (.) hh (.) Uh obviously you two have got a lot of history and uh I

7.

8.

9. Jordan

10. Med

11. Jordan

12. Med don't know all of your history (.) um (.) and it it sounds like Jordan you feel (.) you feel that you have tried to talk.

\section{[I have tried}

[and to mediate (.) Um (.) you are here, yeah you are both here today

[Yeah

[and you are trying

Jordan is describing a past unsuccessful attempt to resolve contact disagreements in court. It seems probable here that he is addressing Nicola as "you" in line 4, though the mediator responds. He tells of the judge's exhortation to them to "sort it out" and how he would "frown upon" another court appearance, "now I have tried everything" - an extreme case formulation used to legitimate his claim (Pomerantz, 1986). The mediator acknowledges Jordan's effort, and the long history. She suggests that the activity of being in the mediation session means that Jordan is indeed trying to "sort it out" (line 8), which Jordan responds to, "I have tried", and she expands this (line 10), both parents are here, and they are trying. They are making an appropriate effort. There may be no successful "outcome" to the session in terms of agreement over contact, but the parents are demonstrating moral effort, an appropriate orientation to the process. The moral agenda of mediation may be distinct from the outcome-based agenda of the process.

The final extract is from another couple who have not managed to agree about contact after an hour's mediation:

Extract 8: Roberta and Peter (60 minutes into first session)

1. Peter Can I just ask, on that point, about sitting down to eat? Um we (0.2)

2. that's quite flexible if they are exhausted we are both happy for them 
3.

4.

5.

6. Roberta

7. Peter

8. Roberta

9. Med:

10.

11. Roberta

12. Med

13. Peter:

14. Roberta

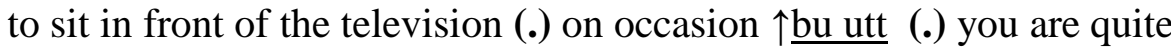
keen (.) and I am no you no I agree with this that (.) with them sitting at a table (.) to eat [to eat as well (.) soo (.)

$[\mathrm{Mhm}$

[that's something you've said

[Hmm. So what's the question

No, it's it's it's an acknowledgement, I think. I heard her. No not you both acknowledged that it's important that they sit at the table

[Yeah

[Is that right? Is that right

Yeah, that's right. $\quad$ [yeah yeah

[absolutely. Absolutely, yeah.

This couple is in the process of separation and discussing contact arrangements and how to agree on parenting rules for mealtimes. Peter gains the floor with "Can I just ask..." and elaborates. He draws on joint agreements, "we are both happy" (line 2) but... at which he describes Roberta's preferences, talking to her directly (not to the mediator), "But you are quite keen" after which there is a series of conversational repairs, "I am no you no I agree" with the children sitting at a table to eat. Roberta provides a minimal response: "Hmm. So what's the question?" At this point, the mediator intervenes. He reframes Peter's missing "question" (set up in line 1 with "can I just ask") as "an acknowledgement, I think". The use of "I heard her" is a regular strategy in therapy or mediation, as a demonstration of acknowledgement - so the mediator is drawing on a therapeutic discourse here. Then the mediator reminds them that they "both acknowledged that it's important that they sit at the table". Here the mediator turns a potential disagreement into a reminder and emphasis of shared parenting values on the topic of "sitting at the table". This reformulation elicits a 
"Yeah" from Roberta, but the mediator presses for further agreement "Is that right. Is that right?" eliciting stronger agreement from both participants. We can see the implicit moral order throughout this discussion, in relation both to parenting practices, and to behavior in the mediation session. As in Extract 5, the mediator here uses the clients' moral ordering as a resource, evaluating and correcting them (Peräkylä and Vehviläinen 2003).

\section{Discussion}

We have studied the talk in family mediation sessions to understand how some of the inherent contradictions between competing core values in mediation, discussed in the introduction, are manifested in mediation talk. We also aimed to highlight some of the mediator strategies employed to manage competing value systems in the mediation process. Some suggested strategies for mediators are included below, as bullet points.

\section{What sort of moral and values talk occur in the mediation data?}

In this mediation data, we see examples of explicitly morally loaded vocabulary raised directly as relevant by participants (trust, "the moral of how he is living"). We also see indirect moral "nudges" by mediators. For example, these mediators' openings contain steers to appropriate behavior in mediation, and include assumptions of appropriate parenting and mediation values. This analysis highlights what constitutes the moral order for parents (what makes a good parent or partner, issues of trust, responsibility, reliability), and the moral order within the mediation context (cooperation in the mediation setting, acceptance of the need to produce agreement, acceptance of the legal "no fault" discourse of post-separation parenting). There are other aspects of the moral order which may be shared, such as the focus on the child's needs and wellbeing, but this is liable to different interpretation by parties and mediators.

Mediators need to further their agenda of producing an agreement, or at least some "progress", while parties appear to use the sessions for other purposes (e.g. here, blame, 
accusations, morally loaded agendas). The obligation to attend to two parties in this multiparty interaction further complicates the process, as ex-partners take up the opportunity to revisit old arguments.

The data illustrates the complex and sometimes contradictory discourses which emerge in the mediation process. For many participants, relationships, marriage and parenting have a demonstrable moral order and this may dominate other concerns. Two of the mothers here - Kerry and Martha - outlined their concerns about the perceived moral failings of their ex-partners as fathers. This morality of parenting and appropriate lifestyle is at odds with the mediation norm of starting by assuming equal suitability for parenting from both parties. The stance of "no fault" in mediation may be a valuable ideal, but in practice it contrasts with participants' moral order, in which moral concerns may "trump" the "no fault" parenting guidelines.

- $\quad$ Training could focus on how mediators can acknowledge the importance of clients' competing values and priorities, but while orienting parties to the primacy (in this context) of the mediation aims and the need for cooperation over future arrangements.

\section{Discourses of trust}

A complex moral discourse which emerged in this data is that of trust. This was alternatively conceptualized as a personal attribute, already proved or not in the relationship (by Kerry and Martha), or as a practice to be (morally) encouraged in post-separation parenting (by mediators). We can see that mediators" references to "trust" were received problematically by participants.

- "Trust" may be an inappropriate or unhelpful word to use, even though it is central to parents' concerns about contact arrangements. This is related to our next point.

\section{Multiple agendas and discourses as a characteristic of the mediation process}


The distinct and not always compatible agendas in this multi-party interaction can also be viewed as a problem of the multi-purpose nature of the mediation process. We saw how mediators may shift strategically between moral, legal and therapeutic discourses (Merry 1990), or shift between pragmatic and emotional positions (Baitar, de Mol and Rober 2016) as a way of managing conflict and disagreement in the sessions (e.g. in Extract 4), but as these different discourses have specific moral orders, this may distract parties from the progression of the mediation goal. Therapeutic discourse may seem appropriate in the context of parties' orientation, but, as shown here, may mean that mediators attend to parties' concerns at the cost of the other party, or of the mediation outcome. In line with other discursive studies, we suggest that neutrality should be seen as an interactional accomplishment (Jacobs 2002; Patrika and Tseliou, 2016). The practical doing of neutrality in mediation has been shown by previous DA studies to be problematic (Greatbatch and Dingwall 1989; 1990).

\section{Mediator strategies for dealing with moral and emotional concerns}

- Mediators may be more effective in presenting an appearance of neutrality if they acknowledge moral and emotional concerns but do not get drawn into moral or therapeutic discourse, instead reframing the topic into more outcome-oriented channels. This is important not just in terms of producing an outcome, but also in terms of the effect on the other party of focusing on blame constructions.

\section{Mediator strategies for producing agreement}

In all the cases here, ex-couples struggled to agree contact arrangements for their children, and our analysis demonstrated some ways in which mediators worked to refocus the discussion towards the mediation goal of producing an agreed outcome. 
- One strategy which mediators used to deal with conversational breakdown was to focus on smaller points which all parties might agree on. This included highlighting shared parenting goals and achievements.

- Another mediator strategy was to reframe talk of blame, or lack of trustworthiness, as a focus on what would be responsible or trustworthy behavior in the future.

\section{Orientation to power dynamics}

As the responses to the mediators' openings demonstrate, parties' perception of whose choice it was to mediate is relevant from the start in terms of power dynamics and feelings of mediator bias, but also in terms of commitment to the mediation "project".

- Who is invited to go first is important; as the first speaker may set the whole agenda. Moreover this is not neutral as it is usually the party who wanted mediation who is invited to go first. Mediators could take care to ensure that the second speaker gets the opportunity to outline their agenda first, before any attempt to respond to the first speaker's agenda.

- The mediator could avoid suggesting agenda items initially, but compromise by noting obvious or important missing items, if they have not been added by parties.

- How parties are invited to set out their agendas is also crucial. In extract 2, the more open choice given to Martha set her off on an unhelpful track of reiterating previous arguments.

This study adds to the recent body of work on interactions in mediation which can be used to inform mediator training and practice (Stokoe 2013; 2014). From a discursive perspective, mediators' orientations, preferred outcomes, and adherence to institutional norms and values are inevitable, so in training an appropriate focus could be on how particular 
discursive positions and strategies can help parties collaborate, and minimize disagreement without dismissing parties' values and positions. The detailed analysis of problem talk that DA facilitates can greatly enhance our understanding of "the complexities and the perplexities" (Patrika and Tseliou 2016) of the mediation encounter. Awareness of the details of interaction can help mediators reflect on and improve their practice, and we suggest that a DA methodology can specifically enhance practitioners' reflexivity about their contributions. We have outlined some mediator strategies in the sections above. Although this paper only draws on family and parenting issues, some of the practices and suggestions are also relevant to wider mediation contexts. The wider study also considered couples who were only dealing with financial issues, and differences in this type of mediation are discussed in Barlow et al (2017).

There are also some implications for policymakers and mediation organizations. Much is claimed in policy terms for mediation (Barlow et al. 2017). It may be useful to clarify the primary orientation of the mediation process, and to accept the power dynamic although family mediation is always supposed to be entered voluntarily, in practice as we saw here, parties often feel constrained to come by financial or legal aspects of the British family justice system (Hunter et al. 2015), even if they are technically "volunteers", and this constraint is manifested in their discourse. Another general point is the importance of all parties agreeing a clear, and shared, agenda from the start, rather than assuming a shared set of values and assumptions. The explicit separation of therapeutic intervention from the mediation sessions (e.g. with multi-service settings) may enable parties to collaborate in the mediation project more productively.

Funding: This work was supported by the Economic and Social Research Council [grant number ES/I031812/1] 
Acknowledgements: Many thanks to the participants - parties and mediators - who consented to these sessions being recorded.

\section{References}

Atkinson, J.M. 1982. "Understanding formality: the categorization and production of 'formal interaction."” British Journal of Sociology 33 (1): 86-117.

Barlow, A., R. Hunter, J. Smithson, and J. Ewing. 2017. Mapping paths to family justice. Resolving family disputes in neoliberal times. Basingstoke: Palgrave Macmillan.

Batitar, R, J. de Mol, J and P. Rober,. 2016. "Exploring helpful tensions between divorce mediators and clients: a relational dialectical analysis." Conflict Resolution Quarterly 34 (1): 7-29.

Bergmann, J. 1998. "Introduction: Morality in discourse." Research on Language and Social Interaction 31 (3/4): 279-294.

Cobb, S., and J. Rifkin. 1991. "Practice and paradox: Deconstructing neutrality in mediation." Law \& Social Inquiry 16 (1): 35-62.

Cromdal, J., and M. Tholander. 2015. "Introduction: Morality in professional practice." Journal of Applied Linguistics and Professional Practice 9 (2): 155-164. 
Dingwall, R., and D. Greatbatch. 1993. "Who is in charge? Rhetoric and evidence in the study of mediation ." Journal of Social Welfare \& Family Law 6: 367-385.

Drew, P., and J. Heritage, eds.. 1992. Talk at work. Cambridge: Cambridge University Press.

Edwards, D. 1999.” Emotion discourse.” Culture \& Psychology 5 (3): 271-291.

Edwards, D. and J. Potter. 2001. "Discursive psychology.” In How to analyse talk in institutional settings: a casebook of methods, edited by A.W. McHoul and M. Rapley, 12-24. London: Continuum.

Ewing, J., R. Hunter, A. Barlow, and J. Smithson. 2015. “Children’s Voices: Centre-Stage or Sidelined in Out-of-Court Dispute Resolution in England and Wales?" Child and Family Law Quarterly 27: 43-61.

Family Mediation Council 2016. Code of Practice for Family Mediators, September 2016 at 5.1.1. (available at http://www.familymediationcouncil.org.uk/us/code-practice/ accessed on 15.11.16)

Garcia, A. C. 1991. "Dispute Resolution Without Disputing: How the Interactional Organization of Mediation Hearings Minimizes Argument.” American Sociological Review 56 (6): 818-835.

Garcia, A. C. 2010. "The role of interactional competence in mediation." Conflict Resolution Quarterly 28 (2): 205-228. 
Garfinkel, H. 1967. Studies in ethnomethodology. Englewood Cliffs, NJ: Prentice-Hall.

Greatbatch, D. And R. Dingwall. 1997. "Argumentative talk in divorce mediation sessions." American Sociological Review 62 (1): 151-170.

Greatbatch, D,.and R. Dingwall. 1989. "Selective Facilitation: Some Preliminary Observations on a Strategy Used by Divorce Mediators." Law and Society Review 23 (4): $613-41$.

Greatbatch, D,. and R. Dingwall. 1999. "Professional neutralism in family mediation.” In: Talk, Work and Institutional Order: Discourse in Medical, Mediation and Management Settings, edited by S. Sarangi and C. Roberts. 271-292. Mouton de Gruyter, Berlin, Germany.

Heritage, J., and D. Greatbatch. 1989. “On the institutional character of institutional talk: The case of news interviews.” Discourse in Professional and Everyday Culture. Linko ping, Department of Communication Studies, University of Linko ping, Sweden, 47-98.

Hunter, R, A. Barlow, J. Smithson, and J. Ewing. 2014. "Mapping Paths to Family Justice: Matching Parties, Cases and Processes.” Family Law 44 (10): 1404-1411.

Hunter, R., A. Barlow, J. Smithson, and J. Ewing. 2015. "Paths to justice in divorce cases in England and Wales." In Delivering Family Justice in the $21^{\text {st }}$ Century. Oxford: Hart Publishing. 
Hutchby, I. 2005. "Active Listening”: Formulations and the Elicitation of Feelings-Talk in Child Counselling.” Research on Language \& Social Interaction 38 (3): 303-329.

Jacobs, S. 2002. "Maintaining neutrality in dispute mediation: managing disagreement while managing not to disagree." Journal of Pragmatics 34: 1403-1426.

Kelly, J. B. 1983. "Mediation and psychotherapy: Distinguishing the differences.” Mediation Quarterly 1 (1): 33-44.

Kurri, K. 2005. "The invisible moral order: agency, accountability and responsibility in therapy talk.” Ph.D. dissertation, University of Jyväskylä.

Kurri, K., and J. Wahlström. 2001. "Dialogical management of morality in domestic violence counselling." Feminism \& Psychology 11 (2): 187-208.

Kurri, K., and J. Wahlström. 2005. "Placement of responsibility and moral reasoning in couple therapy." Journal of Family Therapy 27 (4): 352-369.

Locke, A. 2009. “"Natural versus taught': competing discourses in antenatal breastfeeding workshops.” Journal of Health Psychology 14 (3): 435-446.

McHoul, A,. and M. Rapley. 2005. "A case of attention-deficit/hyperactivity disorder diagnosis: Sir Karl and Francis B. slug it out on the consulting room floor." Discourse \& Society 16 (3): 419-449. 
Merry, S. E. 1990. "Discourses of Mediation and the Power of Naming." Yale Journal of Law \& Humanities 2: 1-36.

Mondada, L. 1998. "Therapy interactions: Specific genre or" blown up" version of ordinary conversational practices?" Pragmatics 8: 155-166.

Patrika, P., and E. Tseliou. 2016. “The 'Blame Game': Discourse Analysis of Family Members' and Therapist Negotiation of Problem Definition in Systemic Family Therapy." The European Journal of Counselling Psychology 4 (1): 101-122.

Peräkylä, A., and S. Vehviläinen. 2003. "Conversation analysis and the professional stocks of interactional knowledge.” Discourse \& Society 14 (6): 727-750.

Pomerantz, A. 1986. "Extreme case formulations: A way of legitimizing claims." Human studies 9 (2-3): 219-229.

Potter, J., and A. Hepburn. 2015. "Somewhere between evil and normal: Traces of morality in a child-protection helpline.” Journal of Applied Linguistics and Professional Practice 9 (2): $81-98$.

Robinson, N. 2012. "Shapeshifters or Polymaths? A Reflection on the Discipline of the Family Mediator in Stephen Cretney's World of Private Ordering." In Fifty Years in Family Law. Essays for Stephen Cretney, edited by R. Probert and C. Barton, 231-247. Cambridge: Intersentia. 
Schegloff, E. A. 2005. “On complainability.” Social Problems 52 (4): 449-476.

Silverman, D. 1994. "Describing Sexual Activities in HIV Counselling: The Cooperative Management of Moral Order.” Text 14: 427-53.

Smithson, J., A. Barlow, R. Hunter, and J. Ewing. 2015. “The 'child's best interests' as an argumentative resource in family mediation sessions." Discourse Studies 17 (5): 1-15.

Sterponi, L. A. 2003. “Account episodes in family discourse: The making of morality in everyday interaction.” Discourse Studies 5 (1): 79-100.

Stokoe, E.H. 2013. “'Overcoming Barriers to Mediation in Intake Calls to Services: ResearchBased Strategies for Mediators.” Negotiation Journal, 29 (3): 289-314.

Stokoe, E.H. 2014, "From talk to text: Using the 'conversation analytic role-play method' to engage (potential) mediation clients in spoken and written communication." Language in Conflict. Available at: http://www.languageinconflict.org (accessed 2 February 2015).

Stokoe, E., and D. Edwards. 2015. "Mundane morality: Gender, categories and complaints in familial neighbour disputes." Journal of Applied Linguistics and Professional Practice, 9 (2): 165-192.

Tjersland, O. A. 1997. "Strategies in mediation explored and developed during a research project." Mediation Quarterly. 15 (2): 105-117.

Van Dijk, T. 1993. "Principles of Critical Discourse Analysis." Discourse and Society 4: 249- 
283.

Walhstrom, J. 2016. "Constructing the moral order in couples therapy.” In Research perspective in couple therapy: Qualitative discursive methods, edited by M. Borsca and P. Rober, 149-165. Heidelberg, Springer.

Webley, L. 2010. "Gate-keeper, supervisor or mentor? The role of professional bodies in the regulation and professional development of solicitors and family mediators undertaking divorce matters in England and Wales." Journal of Social Welfare and Family Law 32 (2): $119-133$

Winslade, J. 2006. "Mediation with a focus on discursive positioning." Conflict Resolution Quarterly 23 (4): 501-515.

\section{Author biographies}

Janet Smithson is a social psychologist, and senior lecturer at the University of Exeter. Her research interests include gender and discourse, online methodologies, and work-life practices and policies.

Anne Barlow is Professor of Family Law at the University of Exeter. She is a socio-legal researcher with interests including cohabitation, family property and pre-nuptial agreements. Rosemary Hunter is Professor of Law at Queen Mary University of London. Her research interests include domestic violence, family justice processes and access to justice. Jan Ewing is a research associate at the University of Exeter, and a qualified solicitor and mediator. Her research interests include marriage and dispute resolutions. 